\title{
Spina Bifida: alternative approaches and treatment, based on evidence through gait analysis
}

\author{
Marcel Rupcich $\mathrm{G}^{\mathrm{a},{ }^{*}}$, Ricardo J Bravo ${ }^{\mathrm{b}, \mathrm{c}}$ \\ ${ }^{a}$ Head of Pediatric Orthopaedic Service, Centro Médico Docente La Trinidad, Venezuela. \\ ${ }^{b}$ Center for Assistive Technology, Universidad Simón Bolivar, Venezuela. \\ ${ }^{c}$ Neurodevelopment Unit, Residencia Humana, Venezuela.
}

\begin{abstract}
Myelomeningocele results from failure of the neural tube to close in the developing fetus and is associated with neurological impairment (Incidence 1:1000 births). The level of the anatomic lesion generally correlates with the neurological deficit and ranges from complete paralysis to minimal or in some cases no motor involvement. Myelomeningocele or Spina bifida can lead to health problems, physical disabilities, and learning problems. Most commonly, associated with paralysis of the lower extremities and neurogenic bladder. Treatment requires multidisciplinary participation. The functional classification that concerns us in this review includes three types and were obtained through gait analysis.
\end{abstract}

Keywords: Spina bifida; instrumental; gait analysis; kinematics and kinetics; orthotics

\section{INTRODUCTION}

The term spinal dysraphism ${ }^{[1]}$ refers to those conditions that result from a defective development in the midline of the dorsal aspect of the embryo, resulting in bone or nervous system deformities. Cutaneous manifestations can be accompanied, but they are not always present.

Spina bifida belongs to a group of developmental disorders of the vertebral arches or the cranial vault. They are often associated with disorders of the formation of structures derived from the neural tube and meninges, and can lead to cystic formations. The causes of spina bifida appear multifactorial. Folic acid deficiency is a significant factor and there appears to be a genetic component.

Three types of spina bifida can be described: The severity ranges from occult, in which no obvious ab-

\footnotetext{
* Corresponding author: Marcel Rupcich G

Mailing address: Department of Pediatrics, Centro Médico Docente La Trinidad, Caracas, Venezuela.

E-mail: marcelrupcich@gmail.com

Received: 24 October 2020 / Accepted: 12 January 2021
}

normalities are seen, to protruding sacs (cystic spina bifida), and to a completely open spine with severe neurological disability and death.

Occult Spina bifida is a defect located in one or more vertebral arches. It develops as a failure of the vertebral arches, remaining unfused in the third month. The spinal cord and meninges remain within the vertebral canal.

The meningocele is a cystic mass of the dura and arachnoid that protrudes through a defect in the vertebral arches under the skin. The spinal cord is completely confined to the vertebral canal, but abnormalities can occur.

Myelomeningocele (MMC), or open spina bifida, where the exposed elements of the spine are fully exposed.

The spectrum of clinical presentation is huge, from lethal rachischisis to asymptomatic occult spina bifida with a small lipoma. The diversity of presentations suggests that causal factors exert their effects in different periods of development, in addition to genetics and the environment that must be considered. Other associated abnormalities found in spina bifida are congenital spinal deformity, Sprengel deformity, tethered cord, neurogenic bladder, and clubfoot. A high incidence of allergy to latex has also been observed. 
Progressive neurological deterioration can occur because hydrocephalus in association with an ArnoldChiari type II defect is common and develops in $80 \%$ of children with thoracolumbar myelomeningocele ${ }^{[2-5]}$.

\section{INSTRUMENTAL GAIT ANALYSIS}

The instrumental gait analysis (IGA) is the record of the biomechanical variables of human movement related to the way we walk. Allowing to know the principles that govern the human movement, making its analysis more objective and able to be measurable.

Nowadays it is compound by:

1. The clinical exam using muscular force measurement through dynamometry;

2. Observational Analysis (three-dimensional video);

3. Kinematics and muscle length;

4. Kinetics;

5. Muscle activity (dynamic EMG);

6. Energy consumption;

7. Baropodography.

This type of analysis has made it possible to identify the prerequisites for normal gait, making it easier to recognize deviations that occur in pathological gait.

\section{FUNCTIONAL IMPACT}

Regarding independence in daily life, at present, the most accepted classification is the one that arises from the available motor function ${ }^{[6-8]}$, so it should be clear what the patient's motor resources are, mainly the antigravity muscles, which are also related to the prognosis of gait and its maintenance over time.

Ambulation is also affected by age, obesity, spasticity, orthopedic deformities, etc. ${ }^{[9]}$ The greater the commitment, the greater the disability and implications such as survival, associated deformities, and the ability to walk.

Motor level and balance are two main factors that compromise the ability to walk and subsequently the degree of support required.

\section{MOTOR LEVEL}

\section{Classification and motor implications}

The level of neurological involvement is one of the key determinants of a child's ambulation.

The most accepted classification of spina bifida is based on the neurological level of the lesion ${ }^{[6-8]}$ (Table 1). Patients are divided into three groups according to the level of injury, functional ability, and ambulation.
As reference, we used the classification proposed by Swank \& Dias ${ }^{[6]}$ to make communication easier and simpler, based on the motor function level (FML) and the functional mobility scale (FMS), which should always be used together.

FML is based on what type of assisted device the patient is using and what type of brace they are wearing, while FMS is based on the ability to walk in three different distances (5/50/500 meters).

The classification criteria for patients, based on the muscle resource present in the lower limbs, are summarized in Table 2.

It is important to note that the lesion tends to be asymmetric in most cases, therefore the classification leans towards the more involved side.

\section{BALANCE}

Balance also affects the ability to walk and the degree of support required and is related to the presence or absence of shunt ${ }^{[10]}$, the function of the shunt and the number of shunt reviews.

Statistical reports from the literature of specialized centers ${ }^{[8]}$ show that of $70-80 \%$ of the lower lumbar level and $98 \%$ of the sacral level retain their ability to walk independently in adult life, whereas thoracic or upper lumbar levels, $7 \%$ lose the ability to walk between 7 and 10 years ${ }^{[6-8]}$.

\section{QUALITY OF AMBULATION AND GAIT ANALYSIS}

Factors affecting gait quality include ${ }^{[11]}$ : muscle weakness, severe scoliosis, flexion contracture of the hip, abduction contracture of the hip, subluxation or dislocation of the hip (with or without soft tissue contracture), rotational deformities of the hip (internal or external) ${ }^{[12]}$, flexion contracture of the knee ${ }^{[13-15]}$ and tibial torsion (internal or external) ${ }^{[16,17]}$. Since a large percentage of outpatients maintain their ability to walk, its quality must be considered. Gait analysis can be used to access and help quantify its quality during ambulation ${ }^{[9]}$.

Generally, a clinical assessment of strength alone rarely reflects the asymmetry noted during gait. An instrumental gait analysis should be the standard of expert care for children with movement abnormalities secondary to spina bifida ${ }^{[18,19]}$.

The IGA has made it possible to measure the impact of the orthoses with the use of kinematics ${ }^{[20]}$ and kinetics on the loads applied to the joints of the lower limbs 
Table 1. Functional classification for outpatients with myelomeningocele.

\begin{tabular}{|c|c|c|}
\hline Group & Level & Comments \\
\hline 1 & $\begin{array}{l}\text { Thoracic/High Lumbar } \\
\text { Level-MM1 }\end{array}$ & $\begin{array}{l}\text { Minimum lower limb motor resource, short-term ambulation. } \\
\text { The highest risk of associated deformities. } \\
\text { Approximately } 7 \% \text { become sedentary between } 7 \text { and } 10 \text { years of age. } \\
\text { No Quadriceps. } \\
\text { Requires reciprocal Gait-Orthosis (RGO), Hip Knee Ankle Foot Orthosis (HKAFO), or Parapodium } \\
\text { FMS: } 2.2 .1 \text {. } \\
\text { Most will stop walking by } 11 \text { to } 13 \text { years of age. } \\
\text { Obesity is common. } \\
\text { Adult: } 99 \% \text { require a wheelchair to mobility (FMS: } 1.1 .1 \text { ). }\end{array}$ \\
\hline 2 & $\begin{array}{l}\text { Low Lumbar } \\
\text { Level-MM2 }\end{array}$ & $\begin{array}{l}\text { Quadriceps and hamstrings function mainly internal: } 70 \% \text { to } 80 \% \text { maintain walking capacity in adulthood. } \\
\text { Hip flexor; knee extensor, and medial Hamstring. } \\
\text { Young patients (FMS: } 3.3 .3,3.3 .1,3.3 .2,2.2 .1 \text { ). } \\
\text { Requires AFO, crutches, walker. } \\
\text { Gluteus maximus and medius: } 2 \text { or less, Gastrocnemius: } 0 \text {. } \\
\text { As they get old, gain weight, and walking decrease (FMS: } 3.3 .1,3.2 .1,2.2 .1,2.1 .1 / 1.1 .1 \text { ). }\end{array}$ \\
\hline 3 & $\begin{array}{l}\text { Sacral Level: } \\
\text { Group I } \\
\text { High Sacral-MM3 } \\
\text { Group II } \\
\text { Low Sacral-MM4 }\end{array}$ & $\begin{array}{l}\text { They practically have a normal gait. } 98 \% \text { maintain walking capacity in adulthood. This group has been } \\
\text { subdivided into two subgroups: } \\
\text { High Sacrum: } \\
\text { Defined by the absence of plantar flexors. } \\
\text { Weak Gluteus Medius and Maximus. } \\
\text { Gastrocsoleus strength } 2 \text { or less. } \\
\text { Requires solid AFO. } \\
\text { Gluteus lurch. } \\
\text { FMS: } 5.5 .5 \text { or } 5.5 .3 \text { or } 6.6 .6 \text {. } \\
\text { Most will retain walking ability as adults. } \\
\text { Low Sacrum } \\
\text { Usual presence of weak plantar flexors or normal strength. } \\
\text { Strong gluteus medius and maximus. } \\
\text { May need SMO/UCBL or no braces. } \\
\text { No Gluteus lurch. } \\
\text { FMS 6.6.6. }\end{array}$ \\
\hline
\end{tabular}

during movement ${ }^{[8,17,21,22]}$. With which the benefit or not, of walking aid options is documented, and their impact on biomechanics ${ }^{[23]}$.

It allows observing the knee moments in the coronal plane to define if there are valgus forces ${ }^{[24]}$, as well as documenting the rotation patterns of the trunk and pelvis in the transverse plane ${ }^{[25]}$ due to the combination of bone deformities and muscle weakness.

IGA also shows muscle function, especially in the ankle, due to muscle hyperactivity, muscle shortening, or weakness ${ }^{[22,26,27]}$ resulting from growth, puberty, or cord retention, when a given treatment is considered. It documents postoperative changes that are used for subsequent decision making. All this information allows the specialist to formulate treatment plans and protocols in order to develop the maximum potential and independence of the patient ${ }^{[8,17,21,22]}$.

\section{EVIDENCE FROM INSTRUMENTAL GAIT ANALYSIS}

This section shows more in-depth the IGA evidence

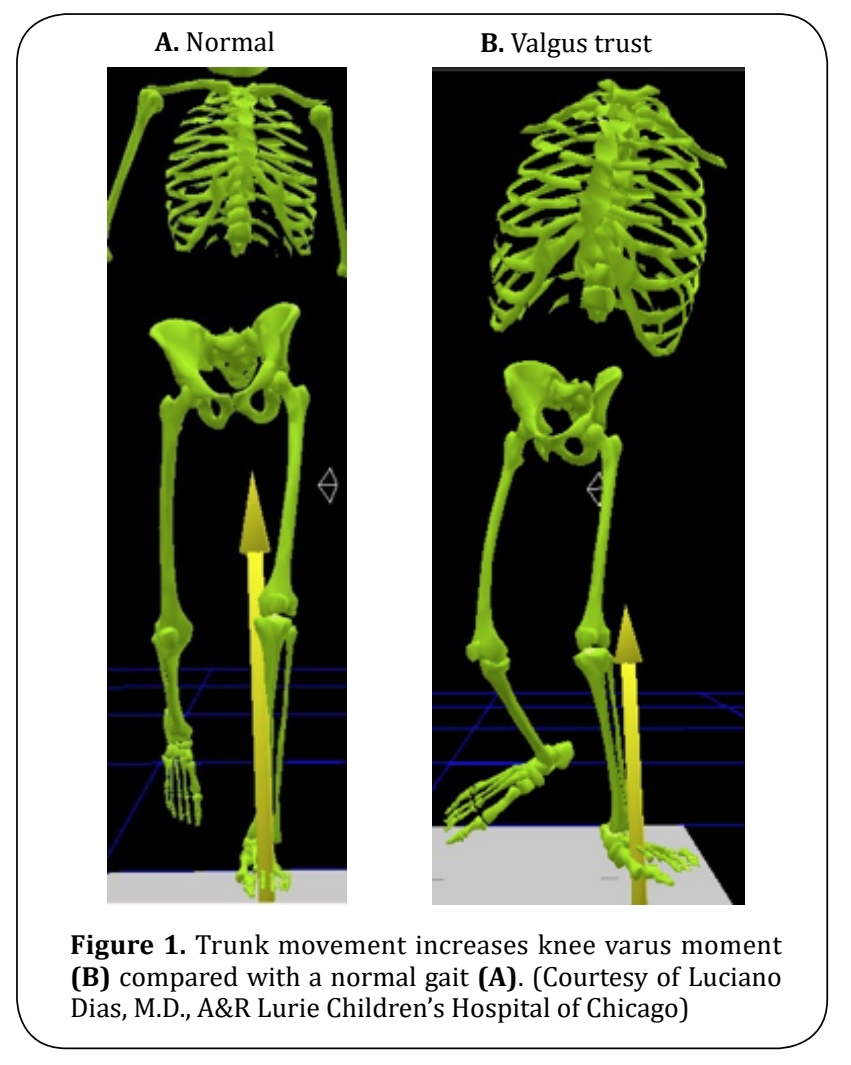


Table 2. Muscle resources versus motor level in myelomeningocele.

\begin{tabular}{lccc}
\hline Muscle group & $\begin{array}{c}\text { Thoracic/High } \\
\text { Lumbar-MM1 }\end{array}$ & Low Lumbar-MM2 & High Sacral-MM3 \\
\hline Hip flexors & May or may not be present & Present & Present \\
Hip adductors & May or may not be present & Present & Present \\
Hip extensors & Absent & Absent & Present \\
Hip abductors & Absent & Absent & Present \\
Knee extensors & Absent & Present & Present \\
Knee flexors & Absent & Medial present \&Lateral & Present \\
& & may or may not & Present \\
Ankle plantar flexor & Absent & Absent & Absent \\
Ankle dorsal flexors & Absent & Absent & May or may not be present \\
\hline
\end{tabular}

Source: authors.

applied to the management of patients with MMC ${ }^{[28]}$, with examples based on gait kinematics and kinetics.

Kinematics and kinetics derived from functional modeling in 3-dimensional instrumental gait analysis provide subject-specific data and can detect not only static but also functional alignment.

Gluteus weakness is the cause of compensation with the lateralization of the trunk during ipsilateral support (Figure 1), also affecting the movements of the pelvis and trunk in the coronal and transverse planes
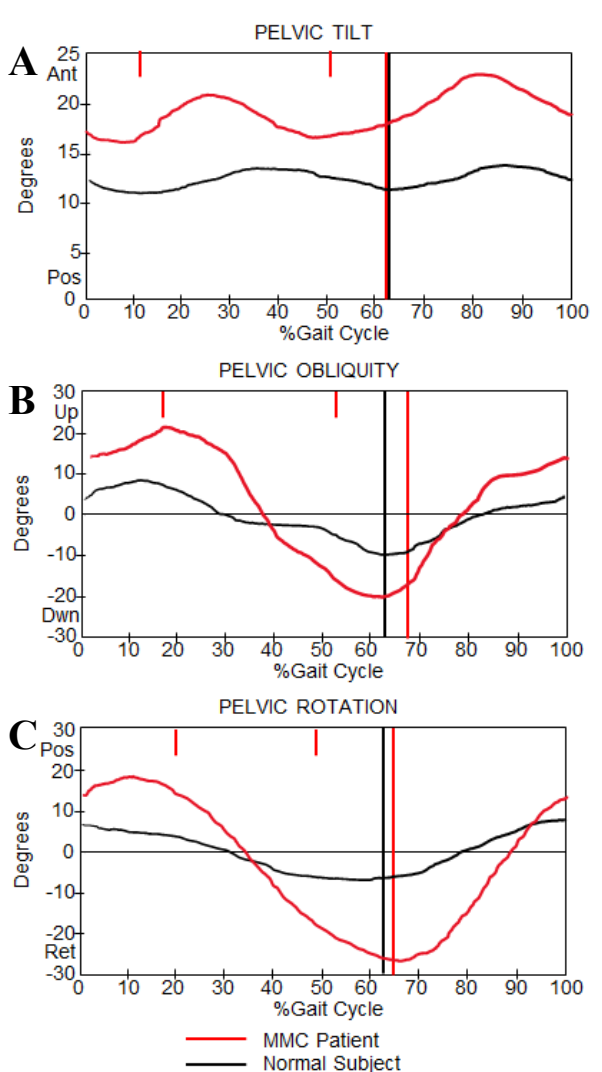

Figure 2. An example of kinematics pelvic obliquity, pelvic rotation and pelvic tilt of an MMC patient vs. normal subject, showing: increased elevation of hemipelvis during the loading response and associate depression of the hemipelvis at toe off. Excessive transverse plane pelvic rotation, increased anterior excursion. (Adapted from Dias et al. ${ }^{[28]}$ ). [excessive pelvic obliquity and rotation (Figure 2), and excessive trunk rotation (Figure 3), in kinematics] and at the knee (increased valgus stress, Figure 4).

The primary factor of the pelvic obliquity (Figure 2B) is the hip abductor weakness which induces a lateral trunk movement over the stance limb. Generally higher levels will show a greater pelvic oblique pattern.

The deviation in the pelvic rotation (Figure $2 \mathrm{C}$ ) is a compensatory motion in the presence of decreased strength of the ankle plantar flexor (primary power generator of walking) and weak hip extensor.

MMC patients show greater than a normal excursion of anterior pelvic tilt progression during single-limb stance (Figure 2A). Its primary factor obeys a decreased hip extensor strength (Gluteus Maximus).

Its primary cause is a weak plantar flexor, and or hip extensor, or quadriceps. Prolonged muscular activity recorded on EMG of the hamstring during the stance phase is needed to control pelvic tilt.

Swing phase pelvic rotation and hip abduction can interrupt the pendulum action of the swing limb. Hip and knee flexor contractures are generally more associated with high levels, affecting the pattern and magnitude of movement.

As can be seen in the graphs of (Figure 6), the pelvic tilt and pelvic rotations increase with the level of the

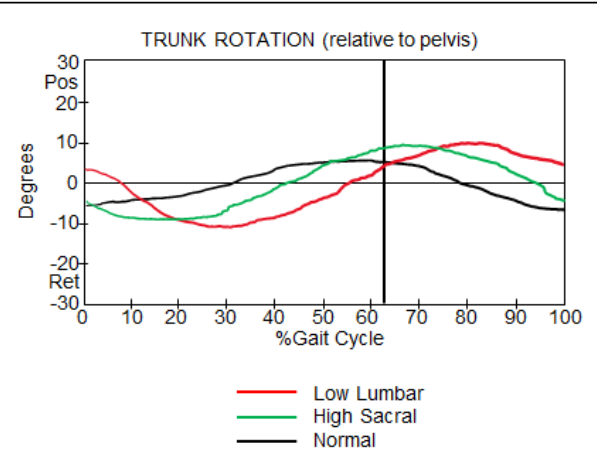

Figure 3. Trunk rotation is relative to the pelvis for different levels of MMC. (Adapted from Dias et al. ${ }^{[28]}$ ). 


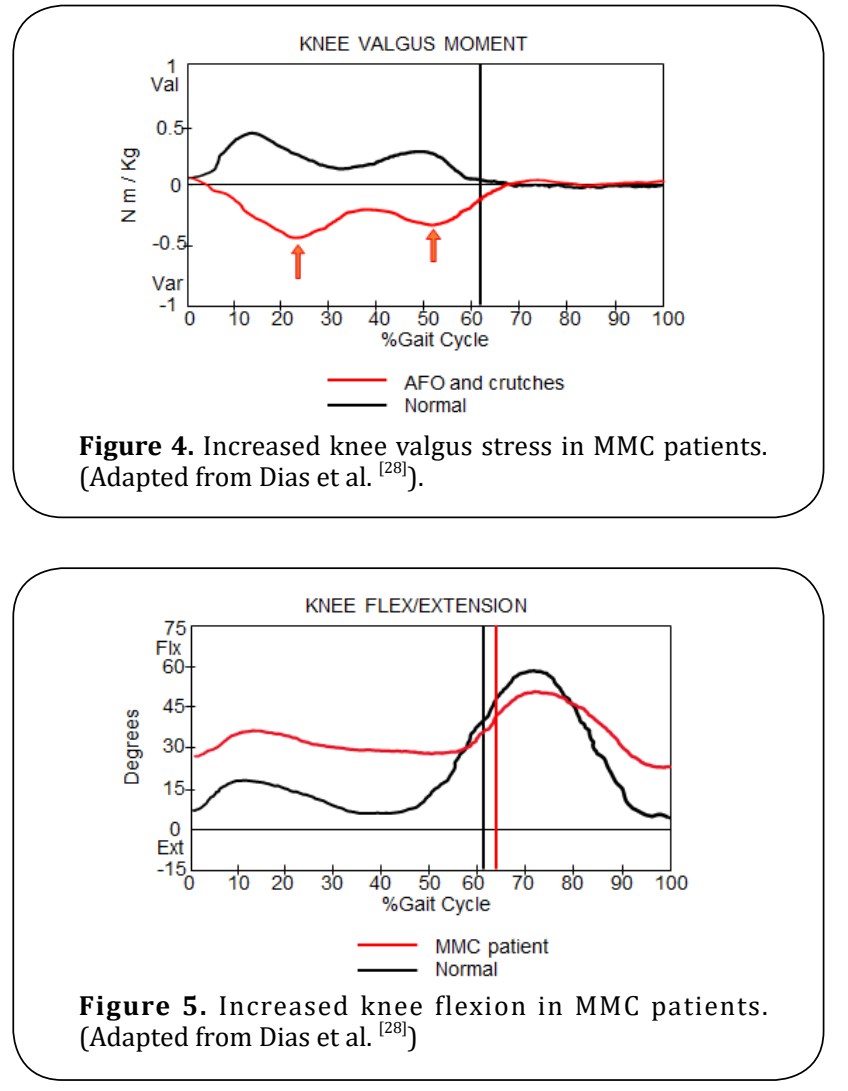

lesion.

IGA also shows the impact of the use of orthosis and additaments (Figure 7). Solid AFOs stabilize the ankle and hindfoot, preventing foot and knee valgus. Crutches decrease trunk movement, therefore, decreasing internal knee varus moment. AFOs also reduce excessive knee flexion in the stance phase as shown in (Figure 8). Due to the increase of the pelvic tilt and pelvic rotations with the level of the lesion shown by kinematics
(Figure 6), a surgery that affects pelvic motion will make the gait more difficult.

Besides, IGA kinetics have demonstrated that any surgery that decreases the strength of power generation muscles (i.e. Ileopsoas, Gluteus, Hamstrings), will affect gait. Transfers of the Iliopsoas muscle (Sherrard procedure) should not be performed as it decreases the flexor power of the hip. Spinal fusion to the Sacrum in low lumbar and sacral level patients must not be performed.

\section{AN OVERVIEW OF CURRENT TREATMENTS}

In this review, we want to show the current state of disease management, its approach with "in utero" interventions, and current treatments based on the knowledge obtained through gait analysis. Existing treatment protocols depend on the anatomical level (muscle resources), balance, and bilaterality or not, present.

Spina bifida is the most common congenital defect, presenting in a wide range of severity and with poor postnatal treatment options. The resolution "in utero" ${ }^{[29-31]}$ have shown beneficial results such as the absence of a sac over the lesion, an improvement in the functional level, per example: an L3 lesion is significantly associated with independent ambulation ${ }^{[2,33]}$. The decrease in the need for ventriculoperitoneal shunts remains controversial, as the incidence or not of Chiari malformation as well ${ }^{[31]}$. Improved surgical techniques have controlled a large percentage of obstetric risks such as premature births and maternal complications derived from the procedure.
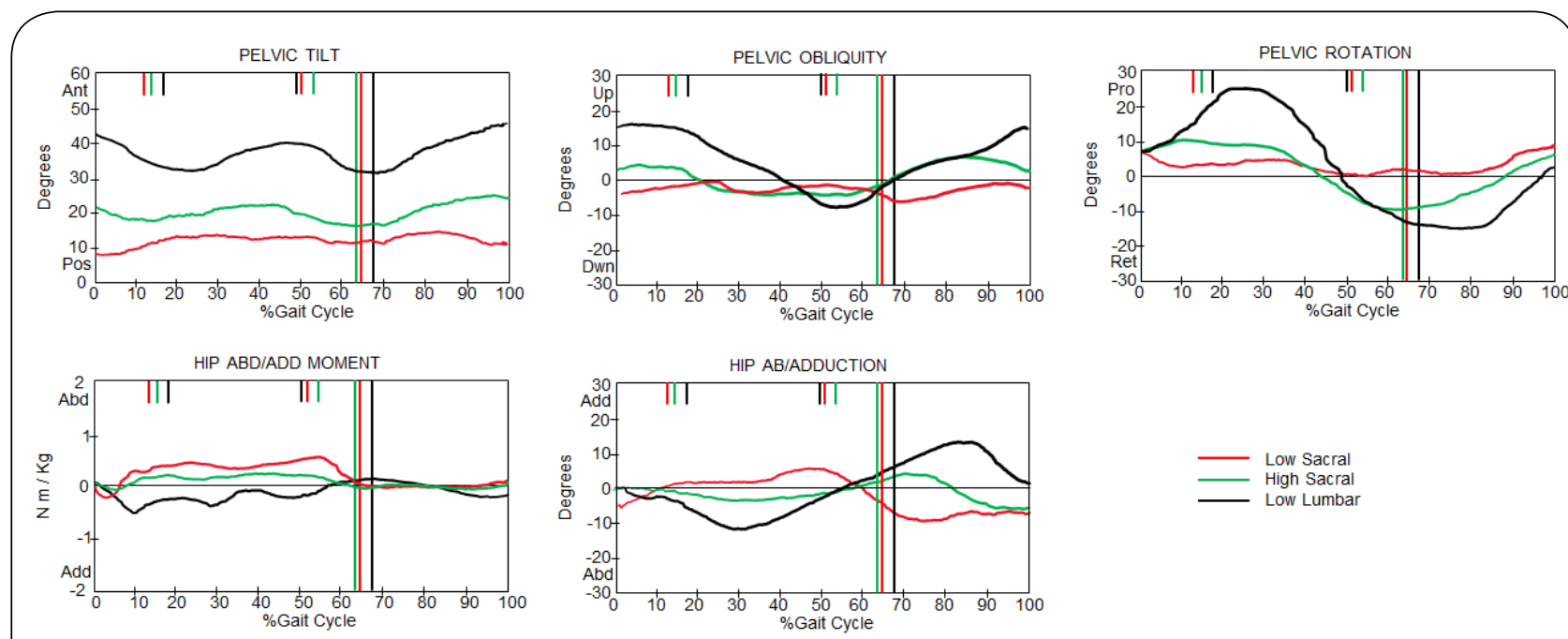

Figure 6. A comparison of gait deviations between MMC levels. (Adapted from Dias et al. ${ }^{[28]}$ ) 

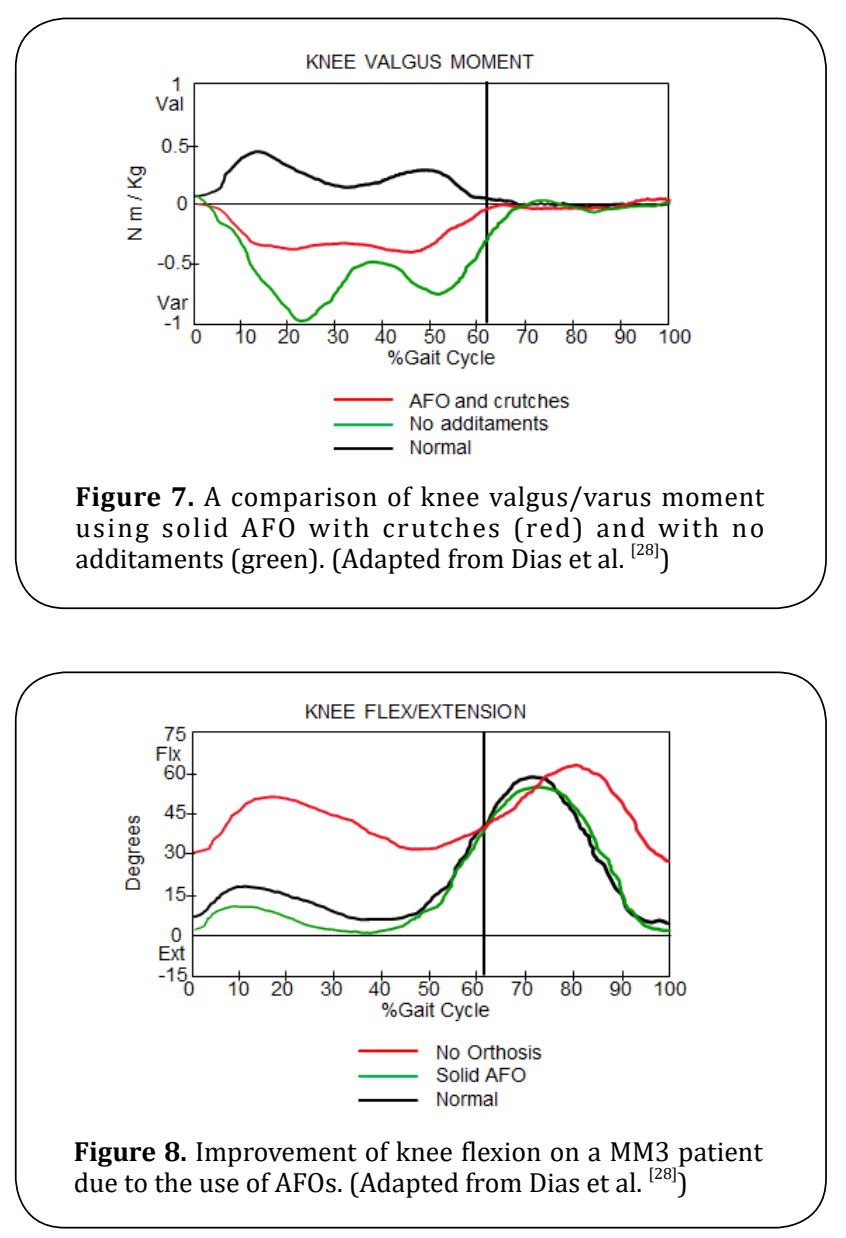

Due to the variety of medical comorbidities involved, for the evaluation and management of these patients, the competence of a multidisciplinary team ${ }^{[34]}$, such as neurosurgery, pediatrics, physiatry, urology, orthopedic surgery, orthotics, physiotherapy, and social work is necessary for appropriate handling.

The goal of the orthopedic surgeon is to correct deformities and improve function and mobility. This is where IGA plays an increasingly important role in behaviors, decision-making, and treatment ${ }^{[35]}$. Decisionmaking about treatment has been made more precise and with better results based on the scientific method, so the inclusion of Instrumental Gait Analysis is essential in the patient care process ${ }^{[36]}$.

Gait analysis enabled to have a better understanding of the gait patterns of each level, allowing to know, which is the best orthosis or additament, and what deformity affects gait and currently has a greater influence on the selection of functional surgical procedures. The results of the instrumental gait analysis often change the identification of pathologies and surgical recommendations, e.g. femoral derotation osteotomy, first metatarsal osteotomy, the release of the plantar fascia,
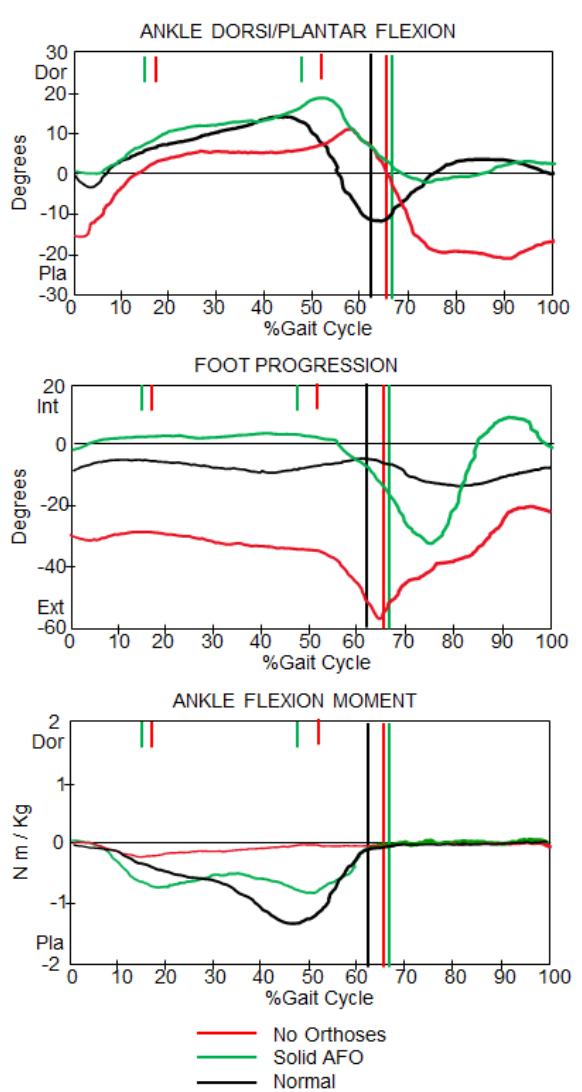

Figure 9. Effect of AFOs in the treatment of an MM3 patient. (Adapted from Dias et al. ${ }^{[28]}$ )

tibial derotation osteotomy, etc ${ }^{[36]}$.

The magnitude of muscle weakness associated with the lesion level is the predominant factor that induces the adapted walking patterns. patients with a low lever lesion typically walk with AFOs and without external support. Higher-level typically walks with AFOs and external support.

The indication of splints on the feet, ankles, and knees is accepted, as long as an improvement in function is demonstrated.

In MM3, the use of the AFO stabilizes the ankle and foot, and its use protects valgus feet and valgus knee. The AFO substitutes for weak ankle plantar flexor in the stance phase (improves the abnormal plantar flexion-knee extension couple) and weak ankle dorsiflexors in the swing phase. The stabilization of the ankle due to AFOs enhances the knee extension in stance (as shown in Figure 8).

AFOs provide (Figure 9) support to prevent foot drop in swing, improves the valgus position of the foot in stance and lever arm of the ankle/foot (resulting in an improvement of ankle plantar-flexor moment and power generation in terminal stance/pre-swing). The 


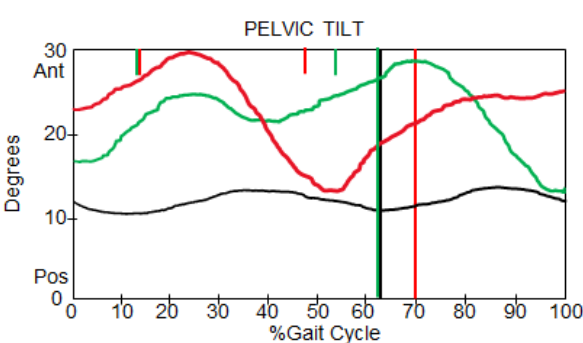

PELVIC OBLIQUITY

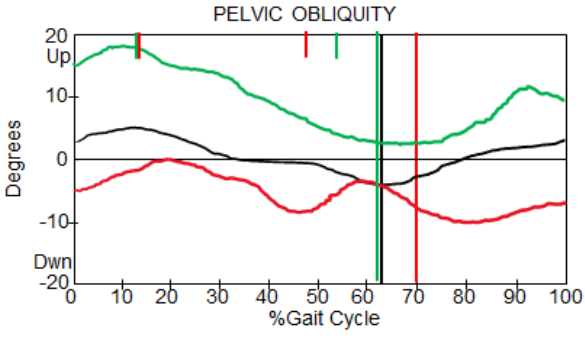

PELVIC ROTATION

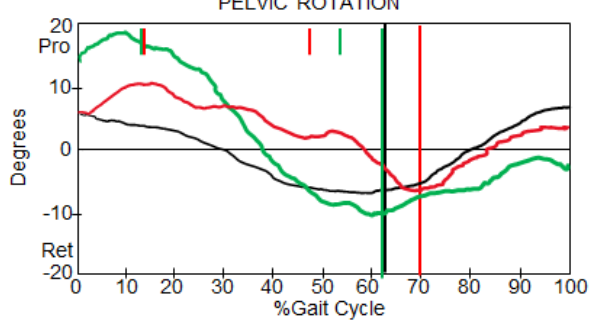

HIP AB/ADDUCTION

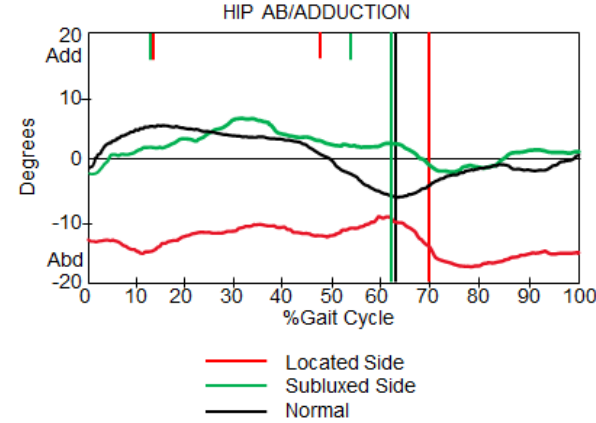

Figure 10. Pelvic kinematics and hip ab/adduction of a located and subluxated hip of an asymmetrical gait MMC patient. (Adapted from Dias et al. ${ }^{[28]}$ )
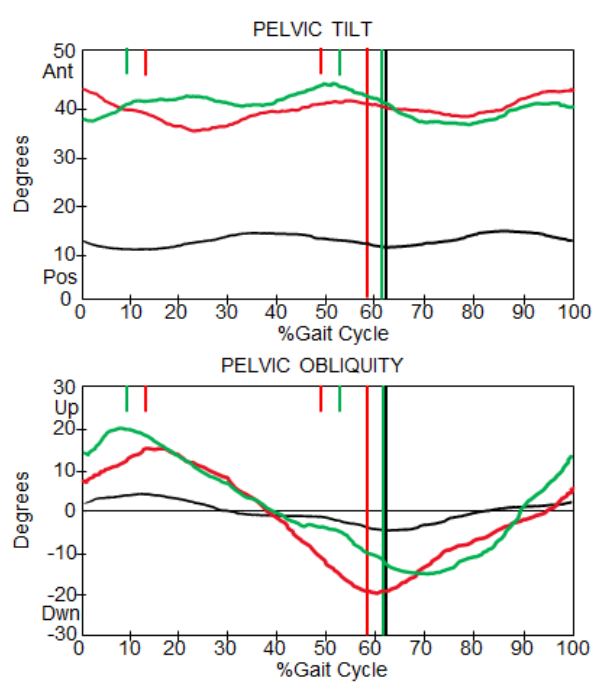

PELVIC ROTATION

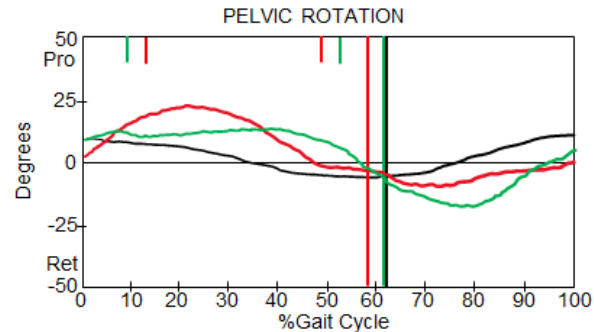

HIP AB/ADDUCTION

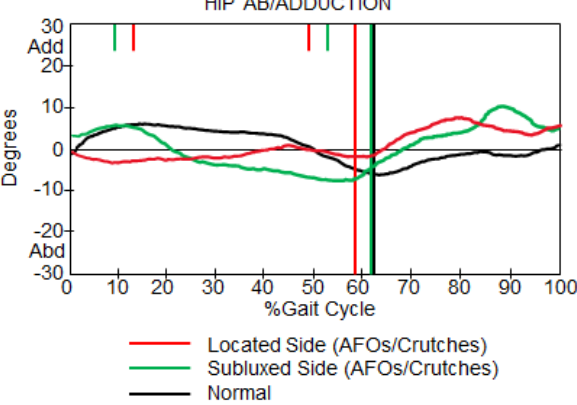

Figure 11. Pelvic kinematics and hip ab/adduction of a located and subluxated hip of symmetrical gait MMC patient. (Adapted from Dias et al. ${ }^{[28]}$ ) following paragraphs show the deformities that can affect the function and how they are treated, such as hip contractures and/or dislocation, knee contractures, rotational deformities of the femur or tibia, and foot deformities.

\section{Hip pathologies}

It is a consensus to treat hip dislocation in patients with L5 level or lower and the release of contractures is limited to being functionally significant.

Hip flexion contracture that produces anterior pelvic tilt from $20^{\circ}-60^{\circ}$, or increased hip flexion in stance which may or may not be associated with increased knee flexion and decreased hip extension. It could be treated with the following procedures: hip flexor lengthening, fascia-lata tensor release, transfer sarto- rius origin to the anterior inferior iliac spine or free tendon graft, the proximal release of rectus femoris, iliopsoas lengthening above the brim, anterior hip capsulotomy (if necessary). In severe cases after hip flexor lengthening, proximal femur extension osteotomy.

The final procedure to be applied to the patient will depend on the surgeon's criteria.

\section{Low lumbar level with unilateral hip subluxation (with hip flexion and adduction contractures)}

Those patients walk with AFOs and crutches with any of these characteristics: asymmetrical hip flexion contractures result in asymmetrical pelvic tilt and/or pelvic rotation, asymmetrical hip adduction contracture results in asymmetrical in pelvic obliquity and/ or hip ab/adduction, leg length discrepancy (may also 


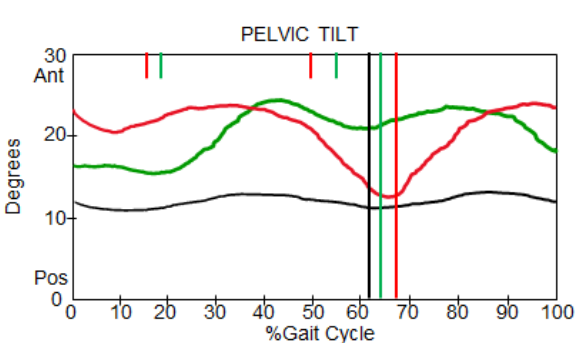

PELVIC OBLIQUITY

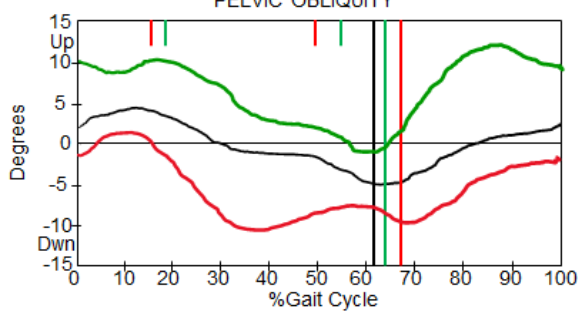

PELVIC ROTATION

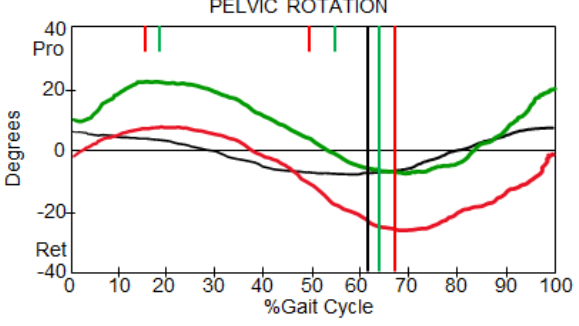

HIP AB/ADDUCTION

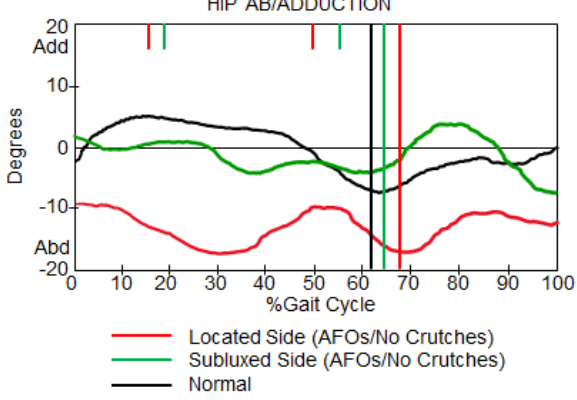

Figure 12. A comparison of a normal pattern vs located and subluxated hips of a MMC sacral level patient using AFOs and no crutches. (Adapted from Dias et al. ${ }^{[28]}$ )

contribute to the gait asymmetry).The treatment may need hip flexor lengthening, adductor myotomy, valgus osteotomy (Shanz) if necessary. Femoral shortening or epiphysiodesis for leg length discrepancy (Figure 10).

\section{Low lumbar level with unilateral hip subluxation (with symmetrical or no contractures)}

These patients walk with AFOs and crutches (some without it) and with symmetrical anterior pelvic tilt, due to symmetrical hip flexion contractures or absence of contractures (Figure 11).

These patients do not need surgical relocation, treat hip flexion contracture if it is above 20 degrees.

\section{Sacral level}

If unilateral hip subluxation and/or dislocation is present, it is important for these patients to rule out a teth-

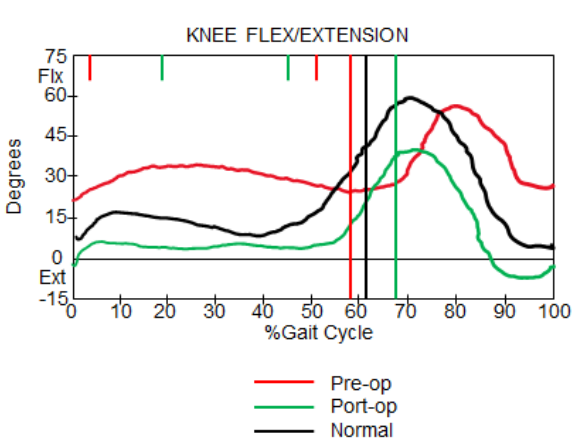

Figure 13. Knee flex/extension of a MMC patient pre and post-surgery vs. a normal pattern. (Adapted from Dias et al. ${ }^{[28]}$ )
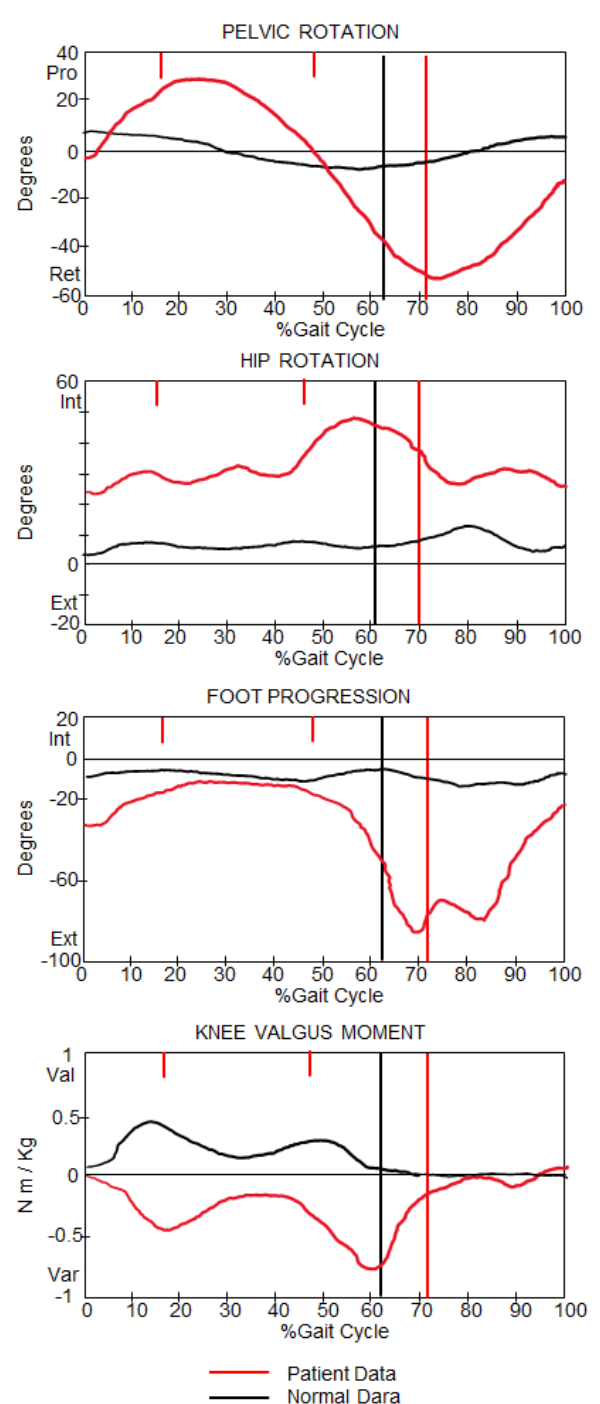

Figure 14. Effects of internal hip rotation and external tibial torsion in knee valgus/varus moment. (Adapted from Dias et al. ${ }^{[28]}$ )

ered cord. Those patients walk with AFOs and without crutches and asymmetric gait patterns in terms of the pelvic obliquity, pelvic rotation, and hip ab/adduction 


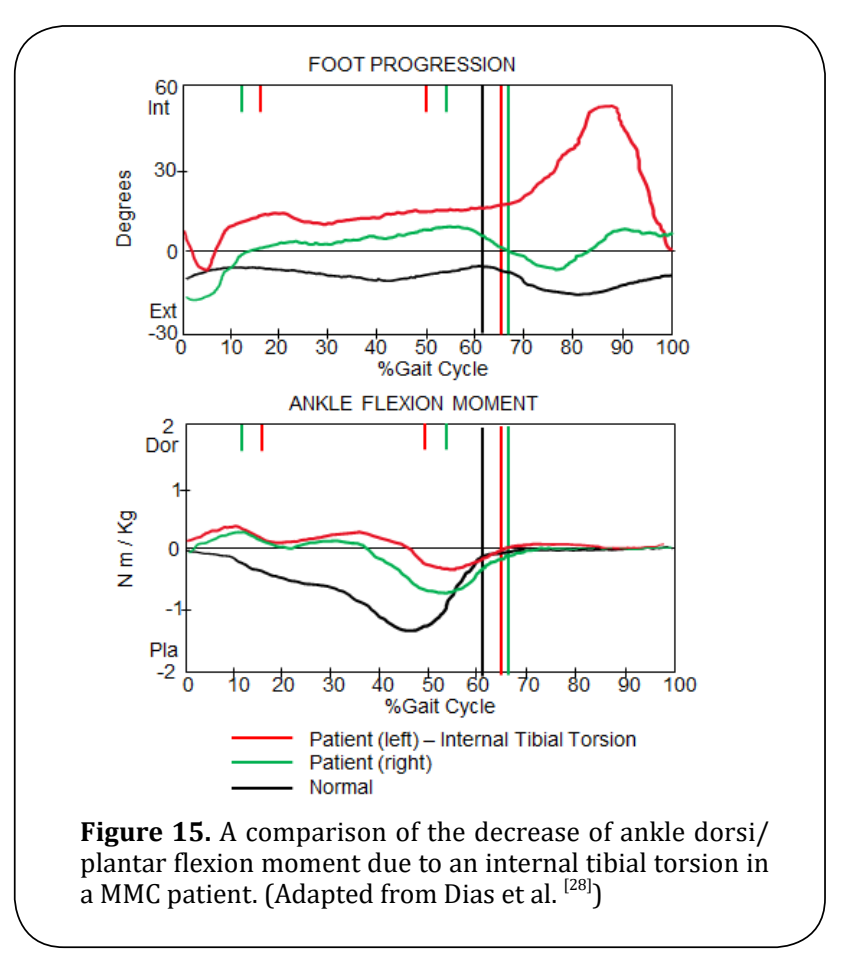

as shown in the following plots (Figure 12).

Depending on the alteration, treatment must include the relocation of the hip, open reduction, pelvic osteotomy (Shelf, Pemberton, Dega, based on surgeon criteria), varus derotation osteotomy (VDO), external oblique transfer or Mustard procedure and treat any of soft tissue contractures.

\section{Knee pathologies}

Knee flexion contracture, will augment the tendency for increased knee flexion which results from weak ankle plantar flexor and hip extensor. The IGA graphs show increased stance phase knee flexion (Figure 13). In consequently the corresponding sagittal plane graphs of hip and knee (not displayed in this document), will show hip flexion and ankle dorsiflexion.

Treatment: orthoses are of limited benefit when knee flexion is equal to or less than 30 degrees. The surgery will be the lengthening of the hamstrings and in extreme cases distal femoral extension osteotomy.

\section{Rotational deformities of the femur and tibia}

\section{Femur}

Internal hip rotation may be present, then foot progression angle varies depending upon the degree of external tibial torsion, and kinetics will show internal varus moment at the knee with external tibial torsion (Figure 14).

Treatment of such deformities is femoral derotation osteotomy. If there is external tibial torsion, tibia/fibu-
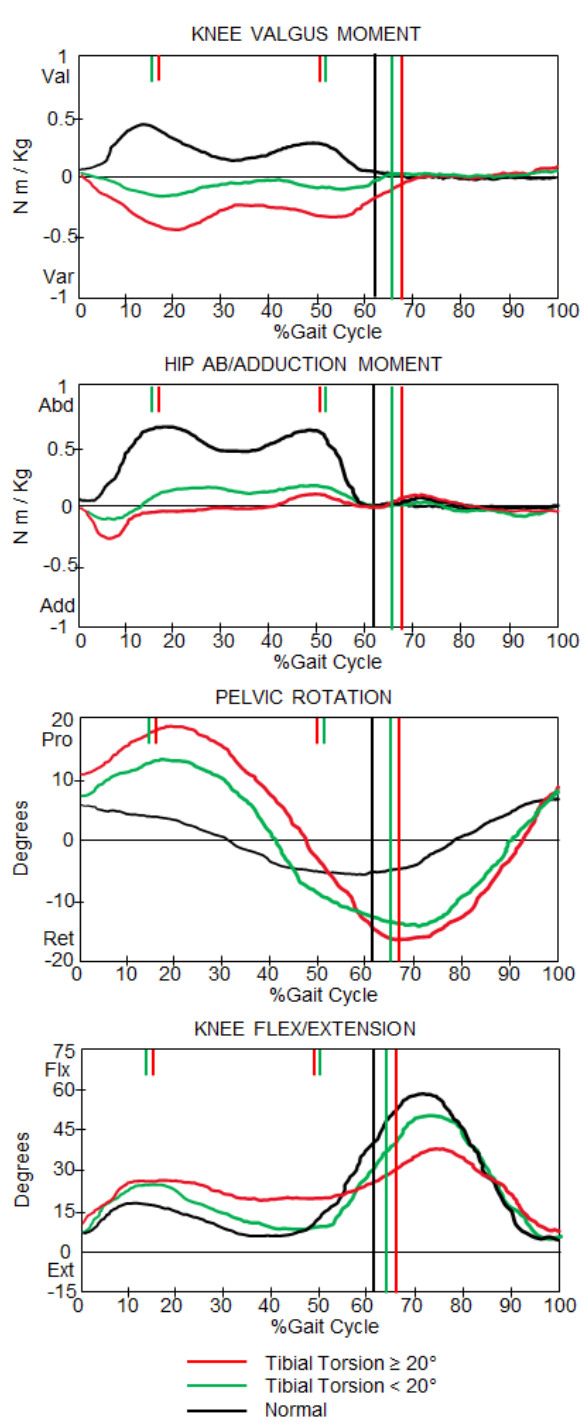

Figure 16. Coronal plane kinetics, pelvic rotation and knee kinematics as a function of external tibial torsion in MMC. (Adapted from Dias et al. ${ }^{[28]}$ )

lar derotation osteotomy must also be considered.

\section{Tibia}

Internal tibial torsion is uncommon in MMC patients. Internal foot progression angle during the swing phase, decreases ankle plantar-flexor moment wave at the terminal stance, as shown in (Figure 15).

The treatment for such cases is the use of orthosis: AFOs, KAFOs depending on level.

External tibial torsions are common in MMC. The magnitude of the external tibial torsion affects the kinetics of the coronal plane (Figure 16), which has been evaluated by several authors ${ }^{[37,38]}$. Other factors must be considered because they are consequences of an external tibial torsion, such as: trunk lean toward in stance phase, dynamic pelvic rotation internal hip rota- 


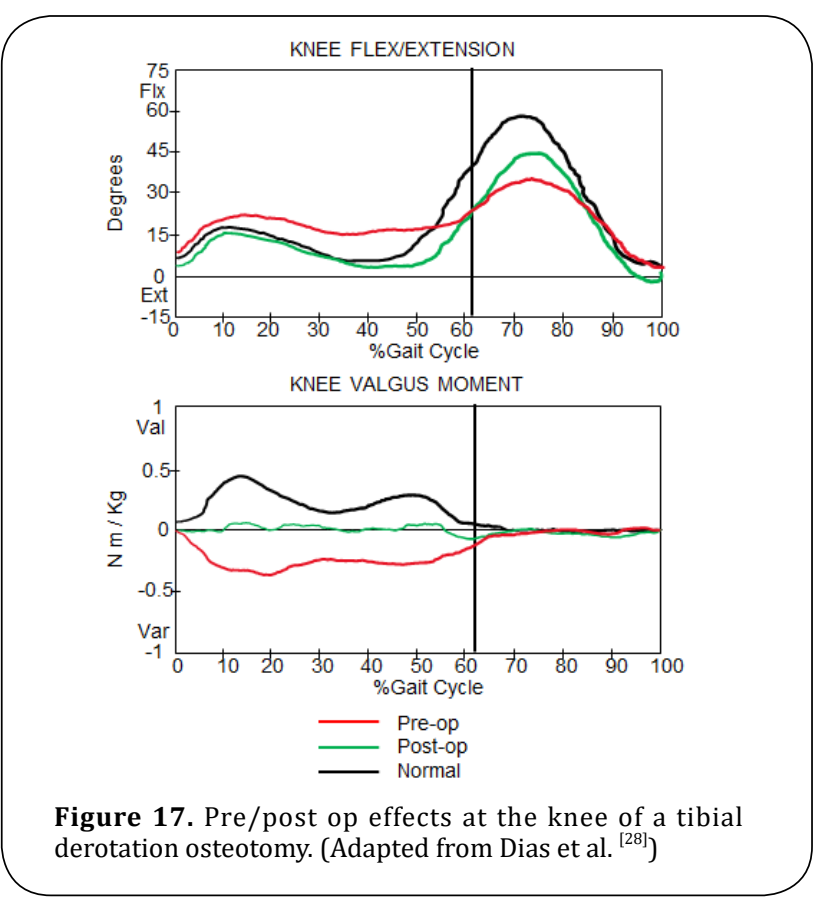

tion, stance phase knee flexion, and ankle and hindfoot valgus.

Treatment of external tibial torsion may be either orthotic or surgical. If it is less than 20 degrees then an AFO/KAFO is recommended. Surgery tIbial/fibular supramalleolar derotation osteotomy should not be done until 5 or 6 years old (Figure 17).

\section{Foot deformities}

Pes valgus is the most common foot deformity, and consists of hindfoot pronation with supination and abduction of the forefoot, producing the same effect in the lower limbs upper segments as the external tibial torsion (knee varus moment). In addition, abnormal ankle plantar flexion-knee extension couple due to loss of lever arm rigidity.

The treatment suggested is anterolateral release secondary to muscle imbalance and progressive deformity, otherwise maintained with UCBL type orthosis until 8 years. After 10 years, an osteotomy of the calcaneus should be considered and the maintenance of UCBL.

Talipes equinovarus present at birth is also frequent. Initially treated with serial casting and continuous splinting until the child is 12 months old, then surgery if needed. Surgery consists of postero medial lateral release with tendon excision.

\section{CONCLUSION}

In general, a clinical evaluation alone rarely provides an approach to compromise in detail what the asym- metries and compensatory responses are used during gait. Instrumental gait analysis should be the standard of care for children with walking abnormalities secondary to spina bifida or any other pathology that alters movement. The main objective of the gait analysis is to define the consequences derived from the neural tube injury in relation to functional activity and future independence of the patient.

Instrumented gait analysis can also provide clinicians with a better understanding of how neurological impairment affects walking, the compensations or compensatory responses used, and further define the functional level of the patient. The current trend is to minimize dependence on orthosis for ambulation during childhood and optimizing mobility and independence within the expectations and functional level of the patient.

Decision-making about treatment has been made more precise and with better results based on the scientific method, so the inclusion of Instrumental Gait Analysis is essential in the patient care process.

\section{DECLARATIONS}

\section{Authors' contributions}

Both authors contributed equally in the development, writing, translation and formatting of this work.

\section{Conflicts of interest}

All authors declared that there are no conflicts of interest.

\section{Ethical approval and informed consent}

Not applicable.

\section{Consent for publication}

Not applicable.

\section{REFERENCES}

1. Menelaus, M. (1980). The Orthopaedic Management of Spina Bifida Systica.

2. Stein, S. C., \& Schut, L. (1979). Hydrocephalus in myelomeningocele. Pediatric Neurosurgery, 5(4), 413-419.

3. Mazur, J. M., Stillwell, A. N. N. E., \& Menelaus, M. A. L. C. O. L. M. (1986). The significance of spasticity in the upper and lower limbs in myelomeningocele. The Journal of bone and joint surgery. British volume, 68(2), 213-217.

4. Mazur, J. M., Menelaus, M. B., Hudson, I., \& Stillwell, A. (1986). Hand function in patients with spina bifida cystica. Journal of pediatric orthopedics, 6(4), 442-447.

5. Roach, J. W., Short, B. F., \& Saltzman, H. M. (2011). Adult consequences of spina bifida: a cohort study. Clinical Or- 
thopaedics and Related Research $®, 469(5), 1246-1252$.

6. Swank, M., \& Dias, L. S. (1994). Walking ability in spina bifida patients: a model for predicting future ambulatory status based on sitting balance and motor level. Journal of pediatric orthopedics, 14(6), 715-718.

7. Dias, L. (2002). Myelomeningocele and intraspinal lipoma. Orthopaedic knowledge update: pediatrics 2nd edn. American Academy of Orthopaedic Surgeons, 249-259.

8. Swaroop, V. T., \& Dias, L. (2009). Orthopedic management of spina bifida. Part I: hip, knee, and rotational deformities. Journal of children's orthopaedics, 3(6), 441449.

9. Baghdadi, T. (2016). Surgical management of hip problems in myelomeningocele: a review article. Archives of Bone and Joint Surgery, 4(3), 197.

10. Swank, M., \& Dias, L. S. (1994). Walking ability in spina bifida patients: a model for predicting future ambulatory status based on sitting balance and motor level. Journal of pediatric orthopedics, 14(6), 715-718.

11. Battibugli, S., Gryfakis, N., Dias, L., Kelp-Lenane, C., Figlioli, S., Fitzgerald, E., ... \& Sullivan, C. (2007). Functional gait comparison between children with myelomeningocele: shunt versus no shunt. Developmental Medicine \& Child Neurology, 49(10), 764-769.

12. Asher, M. A. R. C., \& Olson, J. O. Y. C. E. (1983). Factors affecting the ambulatory status of patients with spina bifida cystica. The Journal of bone and joint surgery. American volume, 65(3), 350-356.

13. Dunteman, R. C., Vankoski, S. J., \& Dias, L. S. (2000). Internal derotation osteotomy of the tibia: pre-and postoperative gait analysis in persons with high sacral myelomeningocele. Journal of Pediatric Orthopaedics, 20(5), 623-628.

14. Westcott, M. A., Dynes, M. C., Remer, E. M., Donaldson, J. S., \& Dias, L. S. (1992). Congenital and acquired orthopedic abnormalities in patients with myelomeningocele. Radiographics, 12(6), 1155-1173.

15. Moen, T., Gryfakis, N., Dias, L., \& Lemke, L. (2005). Crouched gait in myelomeningocele: a comparison between the degree of knee flexion contracture in the clinical examination and during gait. Journal of Pediatric Orthopaedics, 25(5), 657-660.

16. Dias, L. S. (1982). Surgical management of knee contractures in myelomeningocele. Journal of pediatric orthopedics, 2(2), 127-131.

17. Duffy, C. M., Hill, A. E., Cosgrove, A. P., Corry, I. S., Mollan, R. A. B., \& Graham, H. K. (1996). Three-dimensional gait analysis in spina bifida. Journal of Pediatric Orthopaedics, 16(6), 786-791.

18. Dodgin, D. A., De Swart, R. J., Stefko, R. M., Wenger, D. R., \& Ko, J. Y. (1998). Distal tibial/fibular derotation osteotomy for correction of tibial torsion: review of technique and results in 63 cases. Journal of Pediatric Orthopaedics, 18(1), 95-101.
19. Farmer, D. L., Thom, E. A., Brock III, J. W., Burrows, P. K., Johnson, M. P., Howell, L. J., ... \& Management of Myelomeningocele Study Investigators. (2018). The Management of Myelomeningocele Study: full cohort 30-month pediatric outcomes. American journal of obstetrics and gynecology, 218(2), 256-e1.

20. Vankoski, S. J., Sarwark, J. F., Moore, C., \& Dias, L. (1995). Characteristic pelvic, hip, and knee kinematic patterns in children with lumbosacral myelomeningocele. Gait \& Posture, 3(1), 51-57.

21. Dias, L. (2004). Orthopaedic care in spina bifida: past, present, and future. Developmental medicine and child neurology, 46(9), 579-579.

22. Fabry, G., Molenaers, G., Desloovere, K., \& Eyssen, M. (2000). Gait analysis in myelomeningocele: possibilities and applications. Journal of pediatric orthopedics. Part B, 9(3), 170-179.

23. Thomson, J. D., \& Segal, L. S. (2010). Orthopedic management of spina bifida. Developmental disabilities research reviews, 16(1), 96-103.

24. Õunpuu, S., Thomson, J. D., Davis, R. B., \& DeLuca, P. A. (2000). An examination of the knee function during gait in children with myelomeningocele. Journal of Pediatric Orthopaedics, 20(5), 629-635.

25. Bartonek, Å., Saraste, H., Eriksson, M., Knutson, L., \& Cresswell, A. G. (2002). Upper body movement during walking in children with lumbo-sacral myelomeningocele. Gait \& posture, 15(2), 120-129.

26. Gabrieli, A. P. T., Vankoski, S. J., Dias, L. S., Milani, C., Lourenco, A., Laredo Filho, J., \& Novak, R. (2003). Gait analysis in low lumbar myelomeningocele patients with unilateral hip dislocation or subluxation. Journal of Pediatric Orthopaedics, 23(3), 330-334.

27. Gutierrez, E. M., Bartonek, Å., Haglund-Åkerlind, Y., \& Saraste, H. (2005). Kinetics of compensatory gait in persons with myelomeningocele. Gait \& posture, 21(1), 1223.

28. Dias, L., Vankoski, S. J., \& Kelp-Lenane, C. (2000). Myelomeningocele: orthopedic management and gait analysis. American Academy of Cerebral Palsy and Developmental Medicine, Course, 9.

29. Adzick, N. S., Thom, E. A., Spong, C. Y., Brock III, J. W., Burrows, P. K., Johnson, M. P., ... \& Farmer, D. L. (2011). A randomized trial of prenatal versus postnatal repair of myelomeningocele. New England Journal of Medicine, 364(11), 993-1004.

30. Tulipan, N., Wellons, J. C., Thom, E. A., Gupta, N., Sutton, L. N., Burrows, P. K., ... \& Adzick, N. S. (2015). Prenatal surgery for myelomeningocele and the need for cerebrospinal fluid shunt placement. Journal of Neurosurgery: Pediatrics, 16(6), 613-620.

31. Johnson, M. P., Sutton, L. N., Rintoul, N., Crombleholme, T. M., Flake, A. W., Howell, L. J., ... \& Adzick, N. S. (2003). Fetal myelomeningocele repair: short-term clinical out- 
comes. American journal of obstetrics and gynecology, $189(2), 482-487$.

32. Danzer, E., Joyeux, L., Flake, A. W., \& Deprest, J. (2020) Fetal surgical intervention for myelomeningocele: lessons learned, outcomes, and future implications. Developmental Medicine \& Child Neurology, 62(4), 417-425.

33. Houtrow, A. J., Thom, E. A., Fletcher, J. M., Burrows, P. K., Adzick, N. S., Thomas, N. H., ... \& Walker, W. O. (2020). Prenatal repair of myelomeningocele and school-age functional outcomes. Pediatrics, 145(2).

34. Ntimbani, J., Kelly, A., \& Lekgwara, P. (2020). Myelomeningocele-A literature review. Interdisciplinary Neurosurgery, 19, 100502.

35. Wren, T. A., Tucker, C. A., Rethlefsen, S. A., Gorton III, G. E., \& Õunpuu, S. (2020). Clinical efficacy of instrumented gait analysis: Systematic review 2020 update. Gait \& posture, 80, 274-279.

36. Mueske, N. M., Õunpuu, S., Ryan, D. D., Healy, B. S., Thomson, J., Choi, P., \& Wren, T. A. (2019). Impact of gait analysis on pathology identification and surgical recommendations in children with spina bifida. Gait \& posture, 67, 128-132.

37. Shih, Y. C., Chau, M. M., Arendt, E. A., \& Novacheck, T. F. (2020). Measuring lower extremity rotational alignment: a review of methods and case studies of clinical applications. JBJS, 102(4), 343-356.

38. Lim, R., Dias, L., Vankoski, S., Moore, C., Marinello, M., \& Sarwark, J. (1998). Valgus knee stress in lumbosacral myelomeningocele: a gait-analysis evaluation. Journal of Pediatric Orthopaedics, 18(4), 428-433. 